\title{
Effect of Pomegranate Juice Extract on Streptococcus mutans - An In Vitro Study
}

\author{
Rohith A. Nair ${ }^{1}$, Jitheesh Jain ${ }^{2}$, Jaseela Praveena ${ }^{3}$ \\ Pooja M. R. ${ }^{4}$, Shishir Shetty ${ }^{5}$, Aparna H. Gopalakrishnan ${ }^{6}$
}

\begin{abstract}
${ }^{1}$ Department of Conservative Dentistry and Endodontics, A.B. Shetty Memorial Institute of Dental Sciences, Mangalore, Karnataka, India. ${ }^{2,4}$ Department of Public Health Dentistry, Coorg Institute of Dental Sciences, Virajpet. ${ }^{3}$ Department of Public Health Dentistry, K.V.G. Dental College and Hospital, Sullia. ${ }^{5}$ Department of Conservative Dentistry and Endodontics, A.B. Shetty Memorial Institute of Dental Sciences. ${ }^{6}$ Department of Pathology, Mysore.
\end{abstract}

\section{ABSTRACT}

\section{BACKGROUND}

Chlorhexidine the gold standard among anti-plaque agents, though one of the most potent antimicrobial agents, has several drawbacks bringing forth the need for studies focusing on development of new antibacterial agents that are equally or more effective with marginal consequences on the oral tissue. Pomegranate is known for its excellent antioxidant properties and antiplaque effect. Thus, this in-vitro study aims to estimate the influence of pomegranate juice extract mouth rinse (PJE) on $S$. mutans and compare the zone of inhibition of a pomegranate extract mouth rinse with chlorhexidine.

\section{METHODS}

Freshly prepared pomegranate juice was acquired using the sterilised grinder of the research laboratory. $400 \mathrm{~mL}$ of pomegranate juice was heated for $1 \mathrm{hr}$ to get a heavy concentrate. Concentrations of 1200, 900, 600, 300, 150 and $75 \mathrm{mg} / \mathrm{mL}$ was tested. The bacterial strain expended in this study was $S$. mutans microbial type culture collection (MTCC) 890. Five samples of chlorhexidine was taken as control to compare the effect of pomegranate mouth rinse. Mann Whitney U test was employed to compare the antibacterial property between the two groups.

\section{RESULTS}

The zone of inhibition of $S$. mutans using PJE (300 and $600 \mathrm{mg} / \mathrm{mL}$ ) was found to be statistically highly significant $(P=0.008$ and $p=0.007)$ when compared to that of chlorhexidine.

\section{CONCLUSIONS}

PJE mouth rinse possesses remarkable antimicrobial activity against $S$. mutans present in the oral cavity as tested in vitro, and may be used as an adjunct to prevent dental caries and improve oral health.

\section{KEY WORDS}

Antibacterial, Mouth Rinse, pomegranate, PJE, S. mutans
Corresponding Author:

Dr. Jaseela Praveena,

Department of Public Health

Dentistry, K.V.G Dental College

and Hospital, Kurunjibag,

Sullia- 574327, Karnataka.

E-mail: jaz3p91@gmail.com

DOI: $10.14260 /$ jemds/2021/44

How to Cite This Article:

Nair RA, Jain J, Praveena et al. J. Effect of pomegranate juice extract on streptococcus mutans - an invitro study. J Evolution Med Dent Sci 2021;10(04):203-206, DOI: 10.14260/jemds/2021/44

Submission 25-09-2020,

Peer Review 26-11-2020,

Acceptance 04-12-2020,

Published 25-01-2021.

Copyright (C) 2021 Rohith A. Nair et al. This is an open access article distributed under Creative Commons Attribution License [Attribution 4.0 International (CC BY 4.0)] 


\section{BACKGROUND}

Chlorhexidine the gold standard among anti-plaque agent, though one of the most potent antimicrobial agents have several drawbacks such as tooth discoloration, dysgeusia, and augmented calculus development. ${ }^{1}$ Hence bringing forth the need for studies focusing on development of new antibacterial agents that are equally or more effective with marginal consequences on the oral tissue. Streptococcus mutans the major causative factor in dental caries, adheres to the tooth surfaces via water-insoluble glucan from sucrose and is responsible for biofilm formation. ${ }^{2,3}$ Many studies have revealed that $S$. mutans represents about the $20-40 \%$ of the cultivable flora in biofilms removed from carious lesion. ${ }^{4}$ Even though the prevalence of dental caries has remarkably reduced in the past decade through the widespread preventive mechanisms such as use of fluoridated toothpastes and other fluoride containing agents, awareness regarding oral hygiene practices and sealants, it still remains one of the most common chronic diseases both in children and adults alike.5,6 In this era of "turn to your herbal roots" both due to the beneficence of the herbal component and the lack of adverse effect, many herbal products are being studied and considered as antiplaque or antibacterial agents or as adjuvants. Among those herbal alternatives, pomegranate or Punica granatum is one of the most important mentions.

pomegranate is a common fruit widely used in traditional medicine worldwide. In various forms of traditional and oriental medicine, pomegranates are advocated as health supplements and as treatment modality for conditions like diarrhoea, dysentery and diabetes. It is most abundant in phytochemicals such as polyphenols such as the hydrolysable tannins called ellagitannins. Its red color is attributed to anthocyanins such as delphinidin, cyanidin and glucosides. It is used for treatment of various diseases due to its radical scavenging ability, ferrous ion chelating property and ferric ion reducing antioxidant power. ${ }^{7}$ Numerous studies have been done on the antimicrobial properties of pomegranate peel and its curative effects. ${ }^{8-13}$

The antiplaque properties of pomegranate and its use in reducing the risk of gingival and periodontal conditions have been studied extensively. Various studies reports that the antioxidant property attacks the very source of tooth decay at a biochemical level.7,11,13,14,15,16-18 Thus this study was conducted to estimate the influence of pomegranate extract mouth rinse on the $S$. mutans count and to compare the anti caries property of pomegranate extract with chlorhexidine mouth rinse.

\section{METHODS}

An in-vitro study was conducted from $15 / 7 / 17$ to $15 / 10 / 17$. Pomegranate juice extract was freshly prepared at the research laboratory using fresh pomegranate documented as P. granatum obtained from the local market. The whole fruit, including arils, seeds, peel, membrane and rind was cut into small pieces and ground to pulp using a sterilised grinder. It was then filtered initially using a muslin cloth followed by Whatman Grade 1 filter paper. $400 \mathrm{~mL}$ of the obtained pomegranate juice was then heated for one hour to get a heavy concentrate. This was diluted to obtain the required concentrations of $1200,900,600,300,150$, and $75 \mathrm{mg} / \mathrm{mL}$.

A concentration of $75 \mathrm{mg} / \mathrm{mL}$ PJ mouth rinse was prepared by dissolving $4.5 \mathrm{~g}$ of PJE in $60 \mathrm{~mL}$ of distilled water. $150 \mathrm{mg} / \mathrm{mL}$ concentration of PJ was prepared by adding $9 \mathrm{~g}$ of PJE to $60 \mathrm{~mL}$ of distilled water. The $300 \mathrm{mg} / \mathrm{mL}$ concentration of PJ was prepared by dissolving $18 \mathrm{~g}$ of PJE in $60 \mathrm{~mL}$ of distilled water. $36 \mathrm{~g}$ of PJE was used to prepare the mouth rinse of $600 \mathrm{mg} / \mathrm{mL}$ concentration of PJ. A concentration of $900 \mathrm{mg} / \mathrm{mL}$ PJ was obtained by dissolving about $54 \mathrm{~g}$ of PJE in $60 \mathrm{~mL}$ of distilled water. $72 \mathrm{~g}$ of PJE was used to prepare the mouth rinse of $1200 \mathrm{mg} / \mathrm{mL}$ of PJ concentration.

\section{Microorganism and Media}

The bacterial strain expended in this study was $S$. mutans microbial type culture collection 890 . Mitis salivary agar was the culture media used.

\section{Methodology}

The mitis salivary agar plates were spread with cultures of $S$. mutans. The five said concentrations of PJE were taken as test samples and 5 samples of $2 \%$ chlorhexidine were taken as control to compare the effect of pomegranate mouth rinse. The plates were incubated at $37^{\circ} \mathrm{C}$ for 24 hours. The antimicrobial activity of PJE was assessed by measuring the zone of inhibition of $S$. mutans using agar well diffusion method.

\section{Statistical Analysis}

The data collected was analysed using SPSS (Statistical Package for Social Sciences, Version 21). Descriptive statistics was calculated, including, mean standard deviation (SD) and median. Inferential statistics using Mann Whitney U test was employed to compare the mean zone of inhibition between the two independent groups. Level of significance was set at $\leq 0.05$ and confidence interval was $95 \%$.

\section{RESULTS}

An in vitro study was conducted to estimate the effect of pomegranate juice extract mouth rinse on $S$. mutans count and also to compare the antimicrobial effect of a pomegranate juice extract mouth rinse with chlorhexidine.

Mean zone of inhibition of Streptococcus mutans at different concentration of pomegranate juice extract (Table 1)

Table 1 shows that at 1200, 900, 150 and $75 \mathrm{mg} / \mathrm{mL}$ concentration of pomegranate juice extract, there were no zone of inhibition. Zone of inhibition were found in 600 and $300 \mathrm{mg} / \mathrm{mL}(1.94 \mathrm{~cm}$ and $1.42 \mathrm{~cm})$ and standard deviation was found to be 0.19 and 0.13 respectively. Zone of inhibition of chlorhexidine mouth wash (control) was found to be $2.4 \mathrm{~cm}$ with a standard deviation of 0.070 .

Comparison of mean zone of inhibition of pomegranate juice extract ( 300 and $600 \mathrm{mg} / \mathrm{mL}$ ) with chlorhexidine in the inhibition of Streptococcus mutans (Table 2)

Table 2 shows that while comparing the PGE $600 \mathrm{mg} / \mathrm{mL}$ with chlorhexidine (control) the $\mathrm{Z}$ value was found to be - 
2.652 and was found to be statistically highly significant $(\mathrm{P}=$ 0.008). Comparing the PGE $300 \mathrm{mg} / \mathrm{mL}$ with chlorhexidine (control), the $\mathrm{Z}$ value was found to be -2.677 and was found to be statistically highly significant $(p=0.007)$.

\begin{tabular}{|c|c|c|c|}
\hline $\begin{array}{l}\text { Concentrations } \\
(\mathrm{mg} / \mathrm{mL})\end{array}$ & $\begin{array}{c}\text { Mean Zone of } \\
\text { Inhibition }(\mathrm{cm})\end{array}$ & $\begin{array}{l}\text { Standard } \\
\text { Deviation }\end{array}$ & Median \\
\hline 1200 & 0 & 0 & 0 \\
\hline 900 & 0 & 0 & 0 \\
\hline 600 & 1.94 & 0.19 & 2 \\
\hline 300 & 1.42 & 0.13 & 1.5 \\
\hline 150 & 0 & 0 & 0 \\
\hline 75 & 0 & 0 & 0 \\
\hline CHX & 2.4 & 0.07 & 2.4 \\
\hline \multicolumn{4}{|c|}{$\begin{array}{l}\text { Table 1. Mean Zone of Inhibition of Streptococcus mutans at Different } \\
\text { Concentrations of Pomegranate Juice Extract (PGE) }\end{array}$} \\
\hline \multicolumn{3}{|c|}{ Groups } & P Value \\
\hline \multirow{2}{*}{ Chlorhexidine } & \multicolumn{2}{|c|}{ Pomegranate juice extract $600 \mathrm{mg} / \mathrm{mL} \quad-2.652$} & $0.008^{*}$ \\
\hline & \multicolumn{2}{|c|}{ Pomegranate juice extract $300 \mathrm{mg} / \mathrm{mL} \quad-2.677$} & $0.007^{*}$ \\
\hline \multicolumn{4}{|c|}{$\begin{array}{l}\text { Table 2. Comparison of Pomegranate Juice Extract (300 and } 600 \mathrm{mg} / \\
\mathrm{mL} \text { ) with Chlorhexidine in the Inhibition of Streptococcus mutans }\end{array}$} \\
\hline \multicolumn{4}{|c|}{ *highly significant } \\
\hline
\end{tabular}

\section{DISCUSSION}

This study conducted to assess the antibacterial effect of PJE revealed zones of inhibition of $S$. mutans in two concentrations ( 600 and $300 \mathrm{mg} / \mathrm{mL}$ ) however, the results were found to be statistically significant. The findings were in accordance with the results of the study conducted by Pereira 19 wherein inhibition was found at $150 \mathrm{mg} / \mathrm{mL}$ concentration and was not found to be statistically significant. Pereira concluded the study by saying that antibacterial activity of pomegranate can be attributed to polyphenolic flavonoids like punicalagins and ellagic acid present in them. Natural phenol such as ellagic acid is commonly found in numerous fruits and vegetables. However, punicalagins that are unique to the pomegranate are water-soluble, highly bioavailable, and supported by safety data. They possess a very high absorption rate of up to $95 \%$ and have very powerful antioxidant properties of their own. They can further break down into smaller polyphenols known as urolithins that can also be absorbed and metabolised by the body. Another study reported by Umar et $\mathrm{Il}^{13}$ conducted on the effect of pomegranate mouth rinse on Streptococcus mutans count and salivary $\mathrm{pH}$ indicated a reduction in the number of $S$. mutans count 10 min and 60 min after oral rinse implying an inhibitory effect of PJE on bacterial growth thus concluding that pomegranate extract suppresses the ability of microorganisms to adhere to the surface of the tooth. ${ }^{13}$ Pomegranate rinsing is reported to increase the activities of antioxidant enzyme ceruloplasmin in saliva while also lowering activities of alpha-glucosidase enzyme that breaks down sucrose. ${ }^{13}$ This further contributes to the anti-cariogenic effects of pomegranate, which may be utilised to prevent dental caries in individuals. The other factors responsible for the inhibition of $S$. mutans according to literature can be attributed to punicalagins, tannin, ellagic acid and ceruloplasmin present in PJE. These hydrolysable tannins are antibacterial agents that can bind by crossing the microbial cell wall composed of several proteins and polysaccharides and precipitate proteins and suppress many enzymes such as glucosyl transferases. They also form complexes of high molecular weight with soluble proteins thus increasing bacterial lysis and interfering with bacterial adherence. ${ }^{20}$ The arils of the fruit contain lesser concentration of tannins compared to the outer carp. As we have included the whole fruit in our study, it will have its beneficence as well.

Vasconcelos et al and Lansky et $\mathrm{al}^{21,22}$ conducted a study on minimum inhibitory concentration of adherence of Punica granatum extract against $S$. mutans. The result of the study indicated that Punica granatum extract was effective in inhibiting the adherence of the bacterial strains in the presence of sucrose. They concluded that when used regularly in combination with toothpaste, pomegranate containing mouthwash inhibits the activities of the microorganisms that cause plaque thereby may reducing dental plaque and tartar formation. Also, Punica granatum (pomegranate) juice extract had an inhibitory effect on the adherence of commonly found bacterium found in the oral cavity. Moreover, dental products containing natural substances have good market perspective and increased acceptance due to popular knowledge regarding lack of side effects as well as cultural or social values. Another factor increasing the acceptance is the awareness regarding the ill-effects associated with over prescription of antibiotics and the increasing resistance developed by micro-organisms against antimicrobials. Hence use of plants and plant derivatives which possess preventive and therapeutic effects to improve oral health can be utilised as alternative to conventional treatments and could be introduced in the dental market.23,24

The findings of the present study support the possibility that the Punica granatum (pomegranate) juice extract can be used in the control of bacteria responsible for oral infections such as caries. pomegranate containing mouthwash can also be used as an adjuvant with toothpaste to reduce the dental caries. Numerous studies have reported the effect pomegranate preparations to be effective in controlling inflammation, particularly oral inflammations as well as bacterial and fungal counts in periodontal disease and candida associated denture stomatitis. Hence, pomegranate is beneficial for oral health as well as overall health. ${ }^{25,26,21,27-30}$

\section{CONCLUSIONS}

PJE mouth rinse possesses antimicrobial properties against $S$. mutans present in the oral cavity as tested in vitro, and may be used as an adjunct to prevent dental caries which might help to maintain good oral hygiene. Further investigations should be carried out to find compounds in pomegranate juice extract that help in the prevention of caries.

Data sharing statement provided by the authors is available with the full text of this article at jemds.com.

Financial or other competing interests: None.

Disclosure forms provided by the authors are available with the full text of this article at jemds.com.

\section{REFERENCES}

[1] Balagopal S, Arjunkumar R. Chlorhexidine: The gold standard antiplaque agent. Journal of Pharmaceutical Sciences and Research 2013;5(12):270-4. 
[2] Nishikawara F, Nomura Y, Imai S, et al. Evaluation of cariogenic bacteria. European Journal Dentistry 2007;1(1):31-9.

[3] Bowen WH, Koo H. Biology of streptococcus mutansderived glucosyltransferases: role in extracellular matrix formation of cariogenic biofilms. Caries Research 2011;45(1):69-86.

[4] Jain I, Jain P, Bisht D, et al. Use of traditional Indian plants in the inhibition of caries-causing bacteria Streptococcus mutans. Brazilian Dental Journal 2016;26(2):110-15.

[5] Ferrazzano GF, Scioscia E, Sateriale D, et al. In vitro antibacterial activity of pomegranate juice and peel extracts on cariogenic bacteria. BioMed Research International 2017;2017:2152749.

[6] Bourgeois DM, Llodra JC. Global burden of dental condition among children in ninecountries participating in an international oral health promotion programme. International Dental Journal 2014;64(Suppl 2):27-34.

[7] Ozgen M, Durgaç C, Serçe S, et al. Chemical and antioxidant properties of pomegranate cultivars grown in the Mediterranean region of Turkey. Food Chemistry 2008;111(3):703-6.

[8] Al-Zoreky NS. Antimicrobial activity of pomegranate (Punica granatum L.) fruit peels. International Journal of Food Microbiology 2009;134(3):244-8.

[9] Kanatt SR, Chander R, Sharma A. Antioxidant and antimicrobial activity of pomegranate peel extract improves the shelf life of chicken products. International Journal of Food Science \& Technology 2010;45(2):21622.

[10] Alexandre EMC, Silva S, Santos SAO, et al. Antimicrobial activity of pomegranate peel extracts performed by high pressure and enzymatic assisted extraction. Food Research International 2019;115:167-76.

[11] Dahham SS, Ali MN, Tabassum H, et al. Studies on antibacterial and antifungal activity of pomegranate (Punica granatum L). Am Eurasian J Agric Environ Sci 2010;9(3):273-81.

[12] Lalwani V, Koneru A, Vanishree M, et al. Anti-microbial activity of Punica granatum on streptococcus in dental caries patients and healthy individuals: a comparative study. Journal of Advanced Clinical \& Research Insights 2014;1:94-8.

[13] Umar D, Dilshad B, Farhan M, et al. The effect of pomegranate mouth rinse on Streptococcus mutans count and salivary pH: an in vivo study. Journal of Advanced Pharmaceutical Technology \& Research 2016;7(1):13-6.

[14] Kakiuchi N, Hattori M, Nishizawa M, et al. Studies on dental caries prevention by traditional medicines. Inhibitory effect of various tannins on glucan synthesis by glycosyl transferase from Streptococcus mutans. Chem Pharm Bull (Tokyo) 1986;34(2):720-5.

[15] Prasad D, Kunnaiah R. Punica granatum: a review on its potential role in treating periodontal disease. Journal of Indian Society of Periodontology 2014;18(4):428-32.

[16] Li Y, Wen S, Kota BP, et al. Punica granatum flower extract, a potent alpha-glucosidase inhibitor, improves postprandial hyperglycemia in Zucker diabetic fatty rats. J Ethnopharmacol 2005;99(2):239-44.
[17] Ahuja S, Dodwad V, Kukreja BJ, et al. A comparative evaluation of efficacy of Punica granatum and chlorhexidine on plaque and gingivitis. Journal of the International Clinical Dental Research Organization 2011;3(1):29-32.

[18] DiSilvestro RA, DiSilvestro DJ, DiSilvestro DJ. pomegranate extract mouth rinsing effects on saliva measures relevant to gingivitis risk. Phytotherapy Research 2009;23(8):1123-7.

[19] Pereira JV, Pereira MSV, Sampaio FC, et al. In vitro antibacterial and anti adherence effect of Punica granatum Linn extract upon dental biofilm microorganisms. Braz J Pharmacogn 2006;16(1):88-93.

[20] Machado TB, Pinto AV, Pinto MCFR, et al. In vitro activity of Brazilian medicinal plants, naturally occurring naphtha quinones and their analogues, against methicillinresistant Staphylococcus aureus. Int J Antimicrob Agents 2003;21(3):279-84.

[21] De Souza VLC, Sampaio FC, Sampaio MCC, et al. Minimum inhibitory concentration of adherence of Punica granatum Linn (pomegranate) gel against $S$. mutans, S. mitis and C. albicans. Braz Dent J 2006;17(3):223-7.

[22] Lansky E, Shubert S, Neeman I. Pharmacological and therapeutic properties of pomegranate. In Symposium on production, processing and marketing of pomegranate in the Mediterranean region: advances in research and technology. Séminaires Méditerranéens (CIHEAM) 2000;42:231-5.

[23] Subramaniam P, Dwivedi S, Uma E, et al. Effect of pomegranate and aloe vera extract on streptococcus mutans: an in vitro study. Dent Hypotheses [serial online] 2012;3(3):99-105.

http://www.dentalhypotheses.com/text.asp?2012/3/3/ 99/103920

[24] Gebara ECE, Zardetto CGDC, Mayer MPA. In vitro study of the antimicrobial activity of natural substances against $S$. mutans and S. sobrinus. Braz Oral Res (formerly Rev Odontol Univ São Paulo) 1996;10(4):251-256.

[25] Menezes SMS, Cordeiro LN, Viana GSB. Punica granatum (pomegranate) extract is active against dental plaque. J Herb Pharmacother 2006;6(2):79-92.

[26] Sastravaha G, Yotnuengnit P, Booncong P, et al. Adjunctive periodontal treatment with Centella asiatica and Punica granatum extracts. A preliminary study. J Int Acad Periodontol 2003;5(4):106-15.

[27] Jurenka J. Therapeutic applications of pomegranate (Punica granatum L): a review. Altern Med Rev 2008;13(2):128-44.

[28] Chaudhari BB, Suryawanshi KK, Shinde VB. Health benefits of pomegranate. Indian Farmer 2015;2(9):691-3.

[29] Zarfeshany A, Asgary S, Javanmard SH. Potent health effects of pomegranate. Advanced Biomedical Research 2014;3:100.

[30] Kandylis P, Kokkinomagoulos E. Food applications and potential health benefits of pomegranate and its derivatives. Foods 2020;9(2):122. 